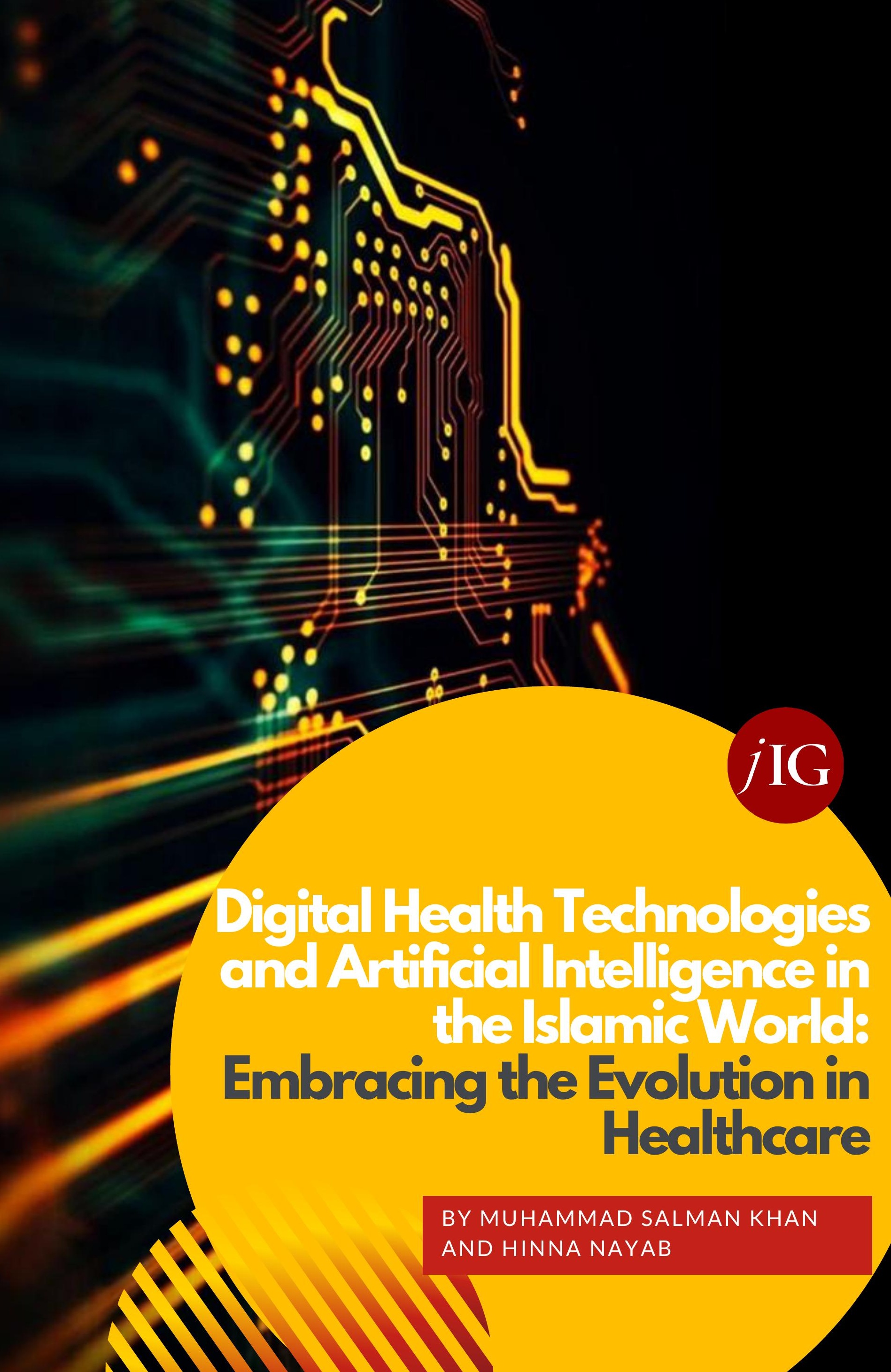




\title{
Digital Health Technologies and Artificial Intelligence in the Islamic World: Embracing the Evolution in Healthcare
}

\author{
Muhammad Salman Khan ${ }^{1}$ and Hinna Nayab²
}

Health and Healthcare have been highly impacted by the global technological revolution resulting in more intelligent systems, optimised hospital workflows, disease prediction and analytics, precision medicine and personalised patient experience. Digital health offers a wide spectrum with artificial intelligence at the far-end having a significant influence on the healthcare systems and medical practice. Artificial intelligence makes sense of the large volumes of medical data through efficient algorithms, thus transforming healthcare systems. But, has the Muslim world been up to date with the advancements in healthcare? This detailed study presents the importance of adopting and adapting to the new technologies in the field of medicine, taking into consideration that Muslim scientists were, in fact, pioneers in the field, carving new medical techniques. The significance of digital health technologies and artificial intelligence in healthcare is also supported by various issues in Muslim societies related to cross-gender patient-doctor interactions, lack of resources, inefficient healthcare systems, and poor socio-economic status. This study concludes with examples of research studies being carried out in the fields of cardiology, haematology, and radiology where algorithms and systems are developed that enable physicians to perform their job with more ease and higher precision.

Keywords: Digital health, artificial intelligence, digital technologies, medicine, healthcare, Islamic governance

\footnotetext{
Correspondence author. The author is an Assistant Professor at the Department of Electrical Engineering, University of Engineering and Technology, Peshawar, Pakistan and Principal Investigator, Artificial Intelligence in Healthcare, Intelligent Information Processing Lab, National Centre of Artificial Intelligence, Pakistan. He is a member of WHO Roster of Experts on Digital Health. salmankhan@utepeshawar.edu.pk.

2 Research Assistant at Artificial Intelligence in Healthcare, Intelligent Information Processing Lab, National Centre of Artificial Intelligence, Pakistan. She earned her Master's in Biomedical Engineering from the National University of Science and Technology, Pakistan
} 

ealthcare is one of the most important aspects of human society. Impairments in physical and mental health are often mitigated through prevention, diagnosis, treatment, recovery and finding a cure for the disease. The diagnosis and detection of an abnormal condition is often a difficult task with the risk factor of misdiagnosis and human errors. ${ }^{1,2}$ Medical practice in recent times has been impacted by the integration of other scientific fields like computational mathematics, statistics, computer science, bioinformatics, and artificial intelligence. ${ }^{3}$ The applications of these fields in medical practice are seen in the form of hospital information systems, data analytics, laboratory computing, computer-assisted decision making, computer-assisted therapy, medical imaging and decision support systems including others. This integration also challenges the traditional ways of diagnosis and treatment and assist in exploring new ways to better the prognosis of a disease. ${ }^{4}$

Globally, digital transformation is shaping up the new normal in healthcare systems and medical science. According to World Health Organization, disruptive digital health technologies like internet-of-things, artificial intelligence, remote monitoring, predictive analytics, smart wearables, and virtual care etc. will enable better health outcomes, improved treatment decisions, optimised management, and patient care in addition to patient-centred healthcare systems. ${ }^{5}$

Artificial Intelligence (Al) is one such disruptive field in healthcare. There is no one definition of Al but generally speaking; Al deals with systems and methods that mimic human behaviour makes informed decisions, and carry out highly complicated tasks effectively. ${ }^{6,7}$ Through $\mathrm{Al}$ and its subdomains, programs are developed that demonstrate intelligence in specific functions including medical diagnosis. An Al-based system will have the traits of problem-solving and depicting human intelligence. There is a shift in healthcare systems

\footnotetext{
1 Steven E Dilsizian and Eliot L Siegel, "Artificial Intelligence in Medicine and Cardiac Imaging: Harnessing Big Data and Advanced Computing to Provide Personalised Medical Diagnosis and Treatment," Current Cardiology Reports (2014): doi:10.1007/s11886-013-0441-8

2 Vimla L. Patel, Edward H. Shortliffe, et al., "The Coming Of Age Of Artificial Intelligence In Medicine," Artificial Intelligence in Medicine 46, 1 (2009): 5-17, doi:10.1016/j.artmed.2008.07.017

3 V. K. Mehta, P.S. Deb and D. S. Rao, “Application of Computer Techniques in Medicine," Medical journal, Armed Forces India 50, 3 (July 1994): 215-218, https://doi.org/10.1016/S0377-1237(17)31065-1

4 Nuria Caballé, Jose Castillo-Sequera, Juan A. Gomez-Pulido, José Gómez and Maria Polo-Luque, "Machine Learning Applied to Diagnosis of Human Diseases: A Systematic Review," Applied Sciences 10, 15 (2020): 5135. 10.3390/app10155135

5 World Health Organization, Global Strategy on Digital Health (2020-2025), World Health Organization, https://www.who.int/docs/defaultsource/documents/gs4dhdaa2a9f352b0445bafbc79ca799dce4d.pdf

6 "The Academic Health Science Network (Al Initiative)," Al in Health and Care, https://ai.ahsnnetwork.com/about/ai-in-health-and-care/

7 “Artificial Intelligence," Merriam-Webster.com Dictionary, Merriam-Webster, accessed 10 Sep. 2020, https://www.merriamwebster.com/dictionary/artificial\%20intelligence
} 
powered by the availability of large volumes of healthcare data and efficient systems encouraged in healthcare institutes and hospitals. Rapid progress has been made in the field of $\mathrm{Al}$ in healthcare with applications ranging from social care and community health like automatic fall detection systems ${ }^{1,2}$ to personalised medicine and automated diagnostic systems. ${ }^{3}$ Algorithms are developed that can act as a decision support system for a healthcare professional and a physician to perform their job with more ease and higher precision. Global market trends show that the Al market will grow to be worth $\$ 16.06$ billion by 2022 with a compound annual growth rate of $62.9 \%$ from the period of 2016 to $2022{ }^{4}$

World Health Organization has declared Al technologies of having the potential for wide applications in health and social care bringing an equally wide range of benefits to patients, their families, communities, and the society at large. In low-middle-income countries, innovative digital technologies are being increasingly implemented to practice and facilitate good governance in healthcare. 5,6 This reinforces the need for digital health technologies implementation in Muslim countries. Islam directs its believers to move with modern times and improve the conditions of their living by adopting the latest advancements in science and technology. ${ }^{7,8}$ Good Islamic governance ensures the integration of religious values and teachings in the Islamic law of a Muslim state. Science and research must be tailored to Muslim countries' own realities and legacy. On a micro-level, this integration in healthcare will require going back to the roots and getting inspired by the great Muslim legacy in technological innovation and medicine.

\footnotetext{
Rabia Hasib, Kaleem Nawaz Khan and Muhammad Salman Khan, "Vision-based Human Posture Classification and Fall Detection using Convolutional Neural Network," Accepted in Proceeding, IEEE International Conference on Artificial Intelligence, (5-7 April 2021)

2 Muhammad Salman Khan, Miao Yu, Pengming Feng, Liang Wang and Jonathon Chambers, "An unsupervised acoustic fall detection system using source separation for sound interference suppression," Signal Processing 110, (May 2015): 199-210

3 Chan Woo Park et al., "Artificial Intelligence in Health Care: Current Applications and Issues," Journal of Korean Medical Science 35,42 (2 Nov. 2020): doi:10.3346/jkms.2020.35e379

4 “5 Al Trends We Can Expect to See in 2017 And Beyond," Alibaba Cloud, 2017, https://www.alibabacloud.com/blog/5-ai-trends-we-canexpect-to-see-in-2017-and-beyond_68685

5 Isaac Holeman, Tara Patricia Cookson and Claudia Plagiari, "Digital Technology for Health Sector Governance in Low- and Middle-Income Countries: A Scoping Review," Journal of Global Health 6, 2 (2016): https://doi.org/10.7189/jogh.06.020408

6 World Health Organization, Handbook of Digital Health Platform: Building a Digital Information Infrastructure (Infostructure) for Health, (2020), https://apps.who.int/iris/bitstream/handle/10665/337449/9789240013728-eng.pdf?sequence=1\&isAllowed=y

7 Wasim Maziak, "Science, Modernity, and the Muslim world: To Improve Scientific Research in Muslim Countries Requires Profound Social and Economic Liberalisation of their Societies," EMBO reports 18, 2 (2017):194-197. https://doi.org/10.15252/embr.201643517

8 "Islam And Science - Concordance or Conflict? The Review of Religions," https://www.reviewofreligions.org/9422/from-the-archives-islamand-science-concordance-or-conflict/
} 


\section{Legacy (Major Advances in Medicine by Muslim Physicians)}

The existence of any kind of disease in any part of the world or any civilisation signifies that there is some form of healing art in practice. ${ }^{1}$ The science of medicine is deeply intertwined with the legacy and teachings of Islam. In Islam, the practice and education of medicine are considered an act of devotion which is founded on the strong principles of faith and trust in Allah. ${ }^{2,3}$ Islam has always encouraged Muslims to seek knowledge and go out into the world in the search of it. The notion that science and technology is a foreign concept in Islam is wrong and baseless. Muslims in the early times have always strived to educate themselves and be better at the new techniques in different fields of science, technology, and medicine. ${ }^{4}$

Art and science have been greatly influenced by the physicians and contributors to the science of the Islamic Golden Age. The concepts such as medical ethics, the conduct of physicians, the relationship between doctor and patient were first introduced in medical science by Muslim scholars and scientists. ${ }^{5}$ The idea of the hospital (Bimaristan or Dar alShifa) being a 'place of the sick' or a 'cure house' was first introduced by the early caliphs and the concept is seen as early as the time of the Prophet Muhammad with His mosque's courtyard being used for the purpose in Madinah. ${ }^{6}$ The hospitals also provided a learning place for future students' training, self-study, patient's record-keeping etc. There was no bias against anyone and nobody was ever turned away.

\section{The Making of The Golden Age}

The Islamic Golden Age spans seven centuries during which Muslim scholars made numerous contributions to medical science. The period produced influential and versatile physicians, astronomers, biologists, chemists and thought leaders. The results and advancements in the Islamic Golden Age were not the products of a few brilliant minds but the contribution and work of students, researchers, scientists, and consumers of science.

\footnotetext{
1 Panda S. C, “Medicine: Science or Art?” Mens sana monographs 4, 1 (2006): 127-138. https://doi.org/10.4103/0973-1229.27610

2 Khalil G. Wakim, "Arabic Medicine in Literature," Bulletin of the Medical Library Association. 32 (1), (1 January 1944), 96-104. ISSN 0025-7338. PMC 194301. PMID 16016635.

3 Hussein G. Rassool, Cultural Competence in Caring for Muslim Patients, (Palgrave Macmillan, 2014): 90-91. ISBN 978-1-137-35841-7

4 Z. Ahsan, The Qur'an, Basic Scientific Research and Technology (perspective), Revelation and Science 3, 1 (2013): 225 - 232.

5 H. Chamsi-Pasha, and M. A. Albar, “Doctor-Patient Relationship. Islamic Perspective," Saudi Medical Journal 37, 2 (2016): 121-126, https://doi.org/10.15537/smj.2016.2.13602

6 Haji Hasbullah Haji Abdul Rahman, "The Development of the Health Sciences and Related Institutions During the First Six Centuries of Islam," International Seminar on Islamic Thought (2004): 973-984
} 
The Islamic Golden Age starts at the end of the seventh century. After Prophet Muhammad passed away in 632AH, Islam started to expand beyond Arabia to other parts of the world including Syria, Iraq, Africa, Persia and Lebanon. ${ }^{1}$ Various ancient compilations of medical literature are reported to be from the seventh century. ${ }^{2}$

In the late eighth century, caliph Hārūn al-Rashīd established Bayt al-Hikmah, The House of Wisdom in the city of Baghdad, Iraq. ${ }^{3}$ The city's scholars were gathered in Bayt al-Hikmah to translate many ancient manuscripts and medical texts. During the eighth century, AlKhwārizmì made significant contributions in the fields of mathematics and science. The words "algorithm" and "algebra" came from Al-Khwārizmīs name and the title of one of his works. ${ }^{4}$

The 9th century saw the rise of another notable Muslim scientist from Persia, Al-Rāzi (latinised, Rhazes). Being a versatile scientist; his work stretched across the areas of physics, chemistry, and medical science. His contributions include many important medical works, later translated into Greek and Latin. One of Al-Rāzi’s greatest works is The Comprehensive Book of Medicine (also known as Continens Liber, The Virtuous Life). ${ }^{5}$ This was a collection of medical notes that Al-Rāzī gathered throughout his life from his readings and practical medical experiences. ${ }^{6}$

Al-Zahrāwī (Abul-Casis) was another great Muslim surgeon, born in Córdoba in the tenth century. He was the inventor of multiple pieces of medical surgery equipment. He was famously known as the "Father of surgery." He wrote the book, Kitab al-Tașrif, the first illustrated surgical guide that was used for teaching many generations of medical science and surgery students. ${ }^{?}$

\footnotetext{
“Early Rise of Islam," (632-700), 2009, https://www.bbc.co.uk/religion/religions/Islam/history/earlyrise_1.shtml

"The Rise of Islamic Empires and States," https://www.khanacademy.org/humanities/world-history/medieval-times/spread-of-Islam/a/therise-of-Islamic-empires-and-states

3 Bahattin Karagözoğlu, Science and Technology from Global and Historical Perspectives, (Springer International Publishing, 2017), 142

4 Fuat Sezgin, Medizin-Pharmazie - Zoologie - Tierheilkunde (Geschichte des arabischen SchrifttumsMedizin): History of the Arabic literature Vol. III: Medicine - Pharmacology - Veterinary Medicine, (Germany: Brill, 1 August 1997), 8-9

5 Selma Tibi, "Al-Razi and Islamic Medicine in the 9th century," Journal of the Royal Society of Medicine 99, 4, (April 2006): 206-208, doi:10.1258/jrsm.99.4.206

6 Abū Bakr Muḥammad ibn Zakarīyā Rāzī, The Comprehensive Book on Medicine, World Digital Library, https://www.wdl.org/en/item/9715/

7 Dr. Sharif Kaf Al-Ghazal, "Al-Zahrawi: A Light in the Dark Middle Ages in Europe," Journal of the International Society for The History of Islamic Medicine, http://www.ishim.net/ishimj/3/08.pdf
} 
In the 11th century, Ibn Sinnā (Avicenna) from Baghdad curated a comprehensive five-volume work encompassing almost all known medical knowledge at the time. This work was called Canon of Medicine. Canon of Medicine became the most famous and celebrated medical works. ${ }^{1}$ Already a doctor at age eighteen, Ibn Sinnā is equally celebrated in Europe and the Western world and is undoubtedly an extraordinary medical scientist of all time. Another notable Muslim physician, philosopher, and astronomer lbn Rushd (Averroës) wrote the medical encyclopaedia known as the Kulliyat (Colliget in Latin) in the 12 th century. ${ }^{2}$ In the 14th century, another notable surgeon, Serefeddin Sabuncuoğlu was born. Sabuncuoğlu created illustrations of advanced procedures of Muslim medicine practices. He is the author of the first surgical atlas, Imperial Surgery. ${ }^{3}$

More extensive medical literature was written in the 13th century by physician Alauddin Ibn al-Nafis. ${ }^{4}$ Alauddin Ibn al-Nafis was the discoverer of the cardiac and pulmonary circulation and authored Mu'giz al-Qanun and Sharh al-Qanun. ${ }^{5}$ Mu'giz al-Qanun was the excerpt of Ibn STnā's famous Canon of Medicine and for several centuries remained a favourite medical manual. ${ }^{6}$

The Islamic golden period lasted for almost seven centuries during which long-lasting medical and scientific contributions were made by Muslim physicians, doctors, and scientists. These contributions had an enduring effect that rippled through the global community and was carried forward into the new era of modern medicine.

\section{Beyond the Islamic Golden Age}

The transition of science and knowledge from East to West happened gradually starting at the end of the 14th century. The myriad scientific innovations of Muslim scientists were

\footnotetext{
1 Mohammad M. Sajadi, Davood Mansouri and Mohamad-Reza M. Sajadi, "Ibn Sina and the Clinical Trial," Annals of Internal Medicine 150, 9, (5 May 2009): 640-643, 10.1.1.690.8376

2 Abdelghani Tbakhi and Samir S Amr. “Ibn Rushd (Averroës): Prince of Science," Annals of Saudi Medicine 28,2 (2008): 145-7. doi:10.5144/02564947.2008.145

3 G. Bademci, "First Illustrations of Female "Neurosurgeons" in the Fifteenth Century by Serefeddin Sabuncuoglu," Neurocirugía 17, 2 (2006): 162-165, doi:10.4321/s1130-14732006000200012

4 Izet Masic, Armin Skrbo, Nabil Naser, Salih Tandir, Lejla Zunic, Senad Medjedovic, and Aziz Sukalo, "Contribution of Arabic Medicine and Pharmacy to the Development of Health Care Protection in Bosnia and Herzegovina - the First Part," Medical Archives (Sarajevo, Bosnia and Herzegovina) 71, 5 (2017): 364-372, https://doi.org/10.5455/medarh.2017.71.364-372

5 Izet Masic, "On Occasion of 800th Anniversary of Birth of Ibn Al-Nafis - Discoverer of Cardiac and Pulmonary Circulation," Med Arh 64, 5 (2010): 309-13

6 Izet Masic, Mirza Dilic, Emir Solakovic, Nedzad Rustempasic, Zoran Ridjanovic, "Why Historians of Medicine Called Ibn Al-Nafis Second Avicenna?" Med Arh 62, 4 (2007): 244-9
} 
deeply rooted in the emerging research and scientific initiatives globally and played a significant role in sparking the European Renaissance. ${ }^{1}$

From the 15th to 21 st century, many contributions were made to medical science. Some highlights will be mentioned. In the 15th and 16th centuries, Paracelsus, a Swiss physician and alchemist by trade; pioneered the usage of minerals and chemicals in the field of medicine. ${ }^{2}$

Hieronymus Fabricius, known as the "Father of Embryology" has cited Al-Zahrāwī (latinised, Abul Casis) in his famous work Surgery by Name. ${ }^{3}$ More developments in medical science happened in the 17th and 18th centuries where Benjamin Bell (1749-1806), a leading surgeon of his time authored $A$ System of Surgery. ${ }^{4}$ He was dubbed as the "Father of a surgical dynasty." In 1796, Edward Jenner developed the smallpox vaccination method. ${ }^{5}$

From the 18th to 21st century, several advancements were made including the discovery of X-Rays and their use in medical imaging by Röntgen (1895), the invention of electrocardiography (ECG/EKG) by William Einthoven (1903), the discovery of the first vaccine for tuberculosis and tetanus (1927), the first commercial ultrasound (1965), completion of the first human genome project (2000) and the use of a 3-D printer for firstever skull transplant (2014) including others. ${ }^{6,7,8}$ These were some of the highlights of the recent work done. The 21 st century looks upon innovative disruptions in the field of medicine forming a base for the re-invention of medical technology.

\section{Technological Advancement in Healthcare}

Medical science and the healthcare industry are heavily influenced by the fourth industrial revolution $(4 \mathrm{IR})$ in the present times. ${ }^{9}$ The $4 \mathrm{IR}$ refers to the on-going automation techniques

\footnotetext{
Jim Al-Khalili, The House of Wisdom: How Arabic Science Saved Ancient Knowledge and Gave Us the Renaissance, (Penguin Publishing Group, 27 March 2012)

2 William Hamilton, The History of Medicine, Surgery, and Anatomy (1831), 17-23

3 Frederic Shepard Dennis, System of Surgery, 1895, 56-57

4 M.D. Leo M. Zimmerman, Ilza Veith, Great Ideas in the History of Surgery, (Norman Publishing, 1 August 1993)

5 Royal College of Physicians of Edinburgh, Edward Jenner (1749 - 1823), https://www.rcpe.ac.uk/heritage/art/jenner-edward-1749-1823

6 Columbia Surgery, History of Medicine: Dr. Roentgen's Accidental X-Rays (Roentgen)

7 The Nobel Prize, William Einthoven (Biographical), https://www.nobelprize.org/prizes/medicine/1924/einthoven/biographical

8 Internet Archive (Wayback Machine), "Timeline: History of Medicine," https://web.archive.org/web/20080222012900/http:/www.abpischools.org.uk/res/coResourcelmport/resources04/history/history2.cfm

9 World Economic Forum, Health and Healthcare in the Fourth Industrial Revolution: Global Future Council on the Future of Health and Healthcare, WEF, 2016-2018
} 
tested and utilised in the manufacturing and industrial practices making complex processes easy to handle. ${ }^{1}$ The basis of the 4IR is formed by the internet-of-things, artificial intelligence, cloud systems and smart digital health technologies. A shift is being observed in the healthcare systems driven by the availability of large volumes of patient and healthcare data. Efficient and interconnected systems, secure data storage(s) and intelligent decision-making systems are the forces behind more ease and higher precision in modern medicine. ${ }^{2}$ The West has adopted the use of these modern smart technologies dealing with the in-rush of data effectively and contributing massively to the development of such technologies. The digital transformation of healthcare enables personalised care and ease of access to doctors for patients, more patient-doctor interaction time, reduced cost of care-delivery, timely diagnosis, and interconnected systems.

The need for Al-based healthcare products and systems is reinforced by the lack of expert physicians, inadequate healthcare systems, poor socio-economic status of the public in most Islamic countries including less developed countries. ${ }^{3}$ In Muslim societies, females avoid visiting doctors due to cultural barriers. Modern digital healthcare technologies enable and empower women in such cases where they can get adequate healthcare services from the comfort of their homes.

\section{Artificial Intelligence in Cardiology, Haematology and Radiology}

The global research community is putting efforts into the implementation of smart digital healthcare technologies. World Health Organization has a Global Digital Health Strategy (2020-2025) whereby guidance for strategy-making and policy-development is provided to set up systems and healthcare ecosystems around the world that enable better healthcare for all using modern technology tools like Al, big data, precision medicine and predictive analytics. ${ }^{4} \mathrm{Al}$ in healthcare covers a wide range of fields. Some global research trends regarding $\mathrm{Al}$ in cardiology, haematology and radiology will be discussed. Cutting-edge research is being carried out in these areas in collaboration with expert healthcare

\footnotetext{
World Economic Forum, "The Fourth Industrial Revolution: What It Means, How To Respond," https://www.weforum.org/agenda/2016/01/the-fourth-industrial-revolution-what-it-means-and-how-to-respond/

2 World Health Organization, Handbook of Digital Health Platform: Building a Digital Information Infrastructure (Infostructure) for Health, (2020), https://apps.who.int/iris/bitstream/handle/10665/337449/9789240013728-eng.pdf?sequence=1\&isAllowed=y

3 Aasim I. Padela and Danish Zaidi, "The Islamic Tradition and Health Inequities: A Preliminary Conceptual Model Based On A Systematic Literature Review Of Muslim Health-Care Disparities, Avicenna," Journal of Medicine, NCBI 8, 1, (2018): doi: 10.4103/ajm.AJM_134_17

4 World Health Organization, “Global Strategy on Digital Health (2020-2025)," World Health Organization, https://www.who.int/docs/defaultsource/documents/gs4dhdaa2a9f352b0445bafbc79ca799dce4d.pdf
} 
professionals for the early diagnosis of related diseases with advanced Al-based diagnostic algorithms.

\section{- Al in Cardiology}

Cardiovascular diseases are a major cause of death in both developing and developed countries. ${ }^{1}$ In the category of non-communicable diseases, almost $37 \%$ of premature deaths are caused by cardiovascular diseases. ${ }^{2}$ In developing countries, the problem is further exacerbated due to limited access to health care facilities and specialists, placing a heavy burden on their economies. Furthermore, the limited availability of specialists results in overburdened cardiologists, affecting the quality of health service and reach.

We live in times of an increased influx of patient data in the form of electronic health records, physiological data like electrocardiograms (ECG), phonocardiogram (PCG), echocardiogram, cardiovascular imaging data, wearables sensors and other clinical data. ${ }^{3}$ With such a vast amount of data, Al becomes vital to the practice of clinical cardiology for increased precision. ${ }^{4}$ Research is being carried out globally by scientists to automatically detect physiological abnormalities of the heart at an early stage using $\mathrm{Al}$ and machine learning techniques. Some examples of such research studies will be discussed. Machine learning and deep learning techniques offer opportunities to automatically diagnose certain cardiac abnormalities with image-based, sound-based, and electrical activity-based methods. Ungru et al. ${ }^{5}$ used an Al-based automatic detection algorithm for the diagnosis of myocardial infarction through echocardiogram data achieving a prediction accuracy of $91 \%$.

Automatic coronary artery disease detection research was carried out by Kukar et al. ${ }^{6}$ using scintigraphy and electrocardiogram data from 327 patients and Shibutani et al. ${ }^{7}$ using the perfusion SPECT data from 21 patients. The results were compared with ICA (Invasive

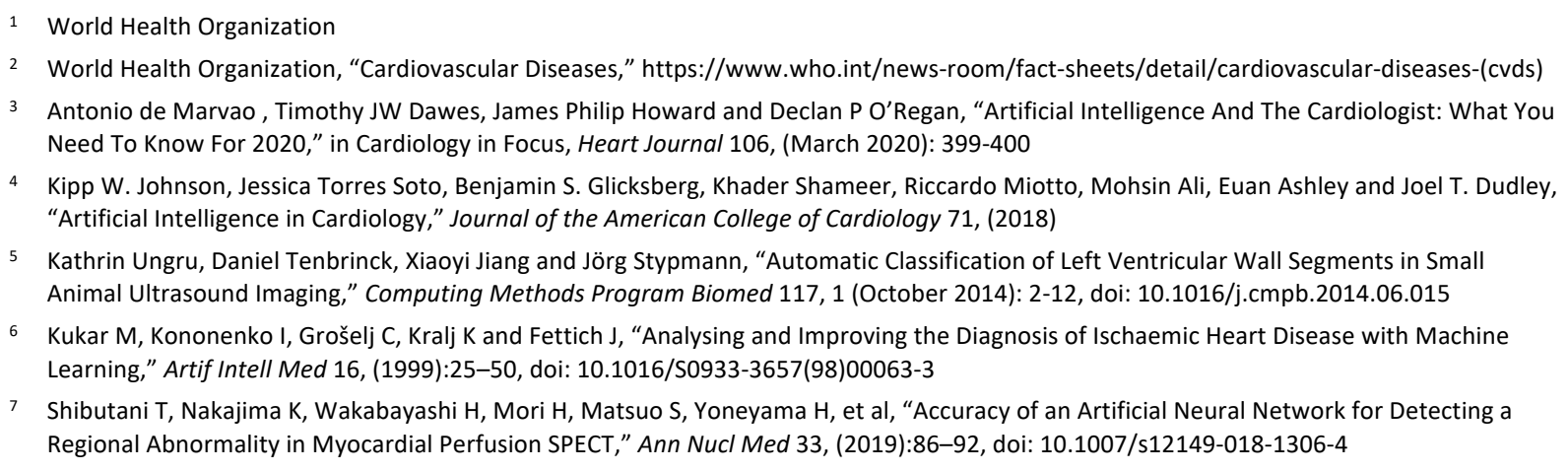

6 Kukar M, Kononenko I, Grošelj C, Kralj K and Fettich J, "Analysing and Improving the Diagnosis of Ischaemic Heart Disease with Machine Learning," Artif Intell Med 16, (1999):25-50, doi: 10.1016/S0933-3657(98)00063-3

7 Shibutani T, Nakajima K, Wakabayashi H, Mori H, Matsuo S, Yoneyama H, et al, “Accuracy of an Artificial Neural Network for Detecting a Regional Abnormality in Myocardial Perfusion SPECT," Ann Nucl Med 33, (2019):86-92, doi: 10.1007/s12149-018-1306-4 
coronary angiography) as a gold standard. Various machine and deep learning models were tested, and, in some cases, the machine learning models outperformed the clinicians' inaccuracy of the diagnosis of coronary artery disease. ${ }^{1}$

Another increasingly common cardiovascular pathology is valvular heart disease that sometimes requires valve replacement. Machine learning integration can assist in the early diagnosis of the condition. Elalfi et al. ${ }^{2}$ used machine-learning-based pre-processing techniques to generate an artificial neural network model with 120 echocardiogram images. The echo images comprised eight different types of heart valvular diseases. Results were promising with the obtained diagnostic accuracy of $93 \%$.

Cardiac arrhythmias are another common abnormality of the heart that can lead to severe complications like atrial fibrillation which increases the risk of stroke. Accurate and early detection of the condition is of prime importance. Jerome et al. ${ }^{3}$ proposed an electrocardiogram-based automatic heart rhythm abnormality detection system. The system consisted of a smart vest with two dry bi-electrodes to collect ECG data which is fed to the automatic diagnostic algorithm (convolutional neural network). The neural network achieved an accuracy of $87.05 \%$ for the detection and classification of heart arrhythmia.

One of the most common methods of detecting heart abnormality is through an auscultation - a process of listening to heart sounds produced by the mechanical activity of the heart using a conventional stethoscope. The conventional stethoscope is very operatordependent and requires expertise to accurately diagnose heart sound abnormalities. Khan et $a l^{4}$ and Dastagir et $a l^{5}$ proposed heart abnormality (cardiac murmurs) detection techniques utilising the acoustic data of the heart, a phonocardiogram (PCG) for automatic classification of heart sounds. The automatic classification was performed using the time

1 Carlos Martin Isla, Victor M. Campello, Cristian Izguierdo, Zahra Raisi-Estabragh, Bettina Baebler, Steffen E. Petersen and Karim Lekadir, "Image-Based Cardiac Diagnosis with Machine Learning: A Review," Cardiovascular Imaging, Frontiers in Cardiovascular Medicine, (24 January 2020)

2 Elalfi A, Eisa M, Ahmed H., “Artificial Neural Networks in Medical Images for Diagnosis Heart Valve Diseases," Int J Comput Sci Issues.10, 83 (2013), https://www.ijcsi.org

3 Jerome Van Zaen, Olivier Chetelat, Mathieu Lemay, Enric M. Calvo, and Ricard Delgado-Gonzalo, "Classification of Cardiac Arrhythmias from Single Lead ECG with a Convolutional Recurrent Neural Network," Electrical Engineering and Systems Science (25 June 2019 ), https://arxiv.org/abs/1907.01513

4 Faiq Ahmad Khan, Anam Abid and Muhammad Salman Khan, "Automatic Heart Sound Classification from Segmented/Unsegmented Phonocardiogram Signals Using Time and Frequency Features," Journal of Physiological Measurement 41, 5 (3 June 2020):055006. doi: 10.1088/1361-6579/ab8770. PMID: 32259811

5 Jehan Dastagir, Faiq Ahmad Khan, Kaleem Nawaz Khan and Muhammad Salman Khan, "Computer-aided Phonocardiogram Classification using Multidomain Time and Frequency Features," Accepted in Proceeding, IEEE International Conference on Artificial Intelligence, (5-7 April 2021) 
and frequency features of the segmented and unsegmented PCG data. Different classification algorithms were tested for evaluation of their performance of the proposed feature subsets.

Another method was proposed by Khan et al. ${ }^{1}$ for deep learning-based classification of the PCG data using the transfer learning method. The proposed approach achieved a high accuracy of more than $95 \%$ in comparison to the other machine learning techniques.

Researchers in Pakistan at Al in healthcare, Intelligent Information Processing Lab² have been heavily engaged in the development of an indigenous Al-powered digital stethoscope, that optimises the functionality of existing electronic stethoscopes by incorporating enhanced visualisation, storage and sharing. A smartphone app is designed to provide wireless auscultation, connection with a secure cloud facility and real-time visualisation of the patient's data received by the digital stethoscope. The product is designed with the needs of the end-user in mind; this includes cardiologists, patients, and doctors under training. The Al model detects abnormalities in real-time, thus supporting the cardiologists in diagnosing the problem while the other smart features ensure seamless processing, storage, management and sharing of critical data between doctors and patients. The aim of the digital stethoscope is two-fold: to provide amplified auscultation and critical diagnostic support in detecting heart abnormalities as a decision support system, and to offer telemedicine services in those areas of the country where specialists and specialised equipment lack. It caters to the pain points of the national demographic and allowing patients to take more control over their cardiac health. The product is protected by pending patent application.

\section{- Al in Haematology}

In the area of haematology, Al and digital tools have been utilised in the routine clinical and laboratory data management, diagnosis of anaemias, thalassaemias and leukaemias using automated techniques for blood tests' analysis. ${ }^{3}$ Thalassemia is a heterogeneous, inherited disorder of haemoglobin synthesis in which one or more globin chains are either not

\footnotetext{
Kaleem Nawaz Khan, Faiq Ahmad Khan, Anam Abid, Tamer Olmez, Zumray Dokur, Muhammad E.H. Chowdhury, and Muhammad Salman Khan, "Deep Learning-Based Classification of Unsegmented Phonocardiogram Sonograms Leveraging Transfer Learning, Revision in Review," Computers in Biology and Medicine, (2021)

2 Artificial Intelligence in Healthcare, Intelligent Information Processing Lab, National Centre of Artificial Intelligence, University of Engineering and Technology, Peshawar, Pakistan

3 Gina Zini, “Artificial Intelligence in Haematology," Hematology 10, 5 (2005): 393-400, DOI: 10.1080/10245330410001727055
} 
produced at all or are produced at a reduced rate. These are classified according to the type of globin chain(s) affected. Globally, an estimated 250 million people carry the gene for thalassemia or abnormal haemoglobin. ${ }^{1}$ The disease is inherited in Mandelian pattern; a child with Thalassemia Major (two affected genes) is born when both partners carry beta thalassaemia trait (one affected gene). ${ }^{2}$ Consanguineous marriages (which constitute 20$50 \%$ of all marriages in Pakistan) have been responsible for the high prevalence of recessively inherited disorders like $\beta$-thalassemia. ${ }^{3}$ According to the World Health Organization, there are approximately 948,000 new carrier couples every year and almost over 1.7 million pregnancies to these couples (75\% being at risk) annually. Globally, governments have successfully employed comprehensive strategies to reduce the incidence of new cases of thalassaemia. In Pakistan however, thalassaemia prevention programs have not met success. These intricate screening programs are based on the collection of blood samples from populations from remote areas, transporting the blood samples to central labs, and analysis of blood on imported equipment. The screening and diagnostic tests require expensive equipment and have high maintenance costs. Furthermore, expert haematologists are required to interpret the results, and efficient logistics are required for reporting the results back to the consumers.

Some research studies concerning automatic Al-based thalassaemia diagnosis will be discussed. These methods and techniques concern the detection of thalassaemia from gel electrophoresis or paper-based haemoglobin electrophoresis. Ivan Bajla et al. proposed a technique for band detection in the gel electrophoresis test images; although users had to perform the selection or rejection of the lane images manually. ${ }^{4}$

Park et al. ${ }^{5}$ proposed a lane extraction method based on the K-mean clustering for estimation of the average lane width. A small portion of the test image was used to calculate the local maxima which served as potential lane centres while segmentation of the lanes

\footnotetext{
1 Michael Angastiniotis, Androulla Eleftheriou, Renzo Galanello, Cornelis L Harteveld, Mary Petrou, Joanne Traeger-Synodinos, Piero Giordano, Eric Jauniaux, Bernadette Modell, Gamel Serour and John Old, Prevention of Thalassemias and other haemoglobin disorders. Second Edition, (Thalassemia International Federation TIF Publication, 2013)

2 Suhaib Ahmed, Zohra Jabeen Wazir and Ishrat Abdul Qayyum, "Clinical and Haematological Picture of Multi-Transfused Thalassemia Major Patients at a Center in Pakistan," JIIMC, Journal of Islamic International Medical college 13, (2018)

3 Umar Saeed and Zahra Zahid Piracha, "Thalassemia: Impact of Consanguineous Marriages on Most Prevalent Monogenic Disorders of Humans," Asian Pacific Journal of Tropical Disease 6, (10 October 2016): 837-840

4 Ivan Bajla, Igor Holländer, and Kornel Burg, "Improvement of Electrophoretic Gel Image Analysis," Meas Sci Rev 1, 1 (2001):5-10

5 Sang Cheol Park, In Seop Na, Tae Ho Han, Soo Hyung Kim, and Guee Sang Lee, "Lane Detection and Tracking in PCR Gel Electrophoresis Images," Computers and Electronics in Agriculture 83, (2012): 85-91
} 
was carried out using local minima. Yang et al. ${ }^{1}$ proposed a pre-processing technique for the gel electrophoresis images. The method involved the removal of the grid texture from the background, calculation of the centre line of the bands and utilisation of the shortest path algorithm for shape recovery.

These techniques perform well with reasonable accuracy, but they require manual input from users for adjustment of the region of interest and set the parameters. To mitigate the shortcomings, Khan et al. ${ }^{2}$ proposed a method for automated assessment of thalassaemia using a deep learning-based convolutional neural network (CNN) from haemoglobin electrophoresis test images. Haemoglobin electrophoresis is a blood test conducted for the detection of thalassaemia. In this research study, an $\mathrm{Hb}$ electrophoresis image dataset was compiled having test results from 824 subjects. Single patient electrophoresis image segmentation and binary classification (normal and abnormal) of the $\mathrm{Hb}$ electrophoresis test images was carried out using CNN models. The obtained accuracy of the automatic assessment was $95.8 \%$.

The researchers at $\mathrm{Al}$ in the healthcare $\mathrm{lab}^{3}$ have been working on the development of a diagnostic device that offers ease of use, i.e., performing the test on this equipment would require minimal training. This device is intended to increase the coverage of the thalassemia screening program. Also, this is a closed system with minimal handling of the blood samples and waste, reducing the risk of exposure to biological hazards. The equipment is connected through the internet to a central screening database for the cataloguing and retrieval of screening data.

Trained personnel will not be required for the diagnostic test(s) as the device will be artificially intelligent; capable of making inferences based on the test's output. The cost of the screening test will be much less than the traditionally performed test(s) at the tertiary care centres. Test turnaround time and reporting time considerably reduced as opposed to the existing devices. The device will also be self-sustained hence easy to take to the out-reach areas where there are limited screening facilities available. The traditional method used to

\footnotetext{
Chih-Yang Lin, Yu-Tai Ching and Yun-Liang Yang, "Automatic Method to Compare the Lanes in Gel Electrophoresis Images," IEEE Transactions on Information Technology in Biomedicine 11, (March 2007)

2 Muhammad Salman Khan, Azmat Ullah, Kaleem Nawaz Khan, Huma Riaz, Yasar Mehmood Yousafzai, Tawsifur Rahman and Muhammad E.H. Chowdhury, "Automated Assessment of Thalassaemia from Haemoglobin Electrophoresis Images using Convolutional Neural Network," IEEE Access (2021)

3 Artificial Intelligence in Healthcare, Intelligent Information Processing Lab, National Center of Artificial Intelligence, University of Engineering and Technology, Peshawar, Pakistan
} 
perform the Electrophoresis test has been optimised and clinically validated for our device. The device will be able to make an automated assessment which reduces the risk for diagnostic errors and the need for trained personnel. This is achieved through the development of the database from the $\mathrm{Hb}$-electrophoresis tests in the form of images to apply the Al algorithm. Improved device design reduces the size and makes it possible to reduce the manual handling of blood. Android App makes it possible for both patients and healthcare providers to get easy access to test results and data. This also serves as a financially viable option for the end-user as patients do not have to travel for follow-up or getting their test reports as they will be provided via app in less than the traditional time. The product and system are protected by pending patent applications.

\section{- Al in Radiology}

Medical imaging plays a vital role in disease identification, early diagnosis, and treatment planning. Biomedical imaging techniques like MRI (Magnetic resonance imaging), CT scans (Computed tomography), and X-Ray images are generally used to monitor disease progression and diagnosis. ${ }^{1}$ Some application areas include segmentation of the malignant region in the brain through $\mathrm{MRI}$, liver, and liver tumour segmentation through CT images and COVID-19 detection through CT images and X-Rays.

\section{Brain Tumour Segmentation}

Brain cancer results in large mortality numbers around the globe and disease incidence has substantially increased in recent years. ${ }^{2}$ Diagnosis and treatment of brain cancer need substantial resource allocation and state-of-the-art diagnostic technology. Automatic screening for brain cancer is essential for the identification and detection of the disease in the early stages.

However, automatic segmentation and identification of a cancerous region in brain MRI is a challenging task due to dependency on the image quality of the MRI. ${ }^{3}$ The bad image quality

\footnotetext{
Anthony Brinton Wolbarst, Looking Within: How X-Ray, CT, MRI, Ultrasound, and Other Medical Images Are Created, and How They Help Physicians Save Lives, First Edition (University of California Press, 16 November 1999)

2 GDB 2016 Brain and other CNS Cancer Collaborators, Global, Regional, and National Burden of Brain and Other CNS Cancer, 1990-2016: a Systematic Analysis for the Global Burden of Disease Study 2016, The Lancet Neurology, 18, 4 (20 February 2019): 376-393

3 Lingling Fang, Xin Wang and Lujie Wang, "Multi-Modal Medical Image Segmentation Based on Vector-Valued Active Contour Model," Information Sciences, (November 2019): 504-518
} 
is because of the presence of noise generated at the time of acquisition and transmission, ${ }^{1,2}$ the inhomogeneous intensity of the MRI, ${ }^{3}$ intensity variability resulted due to different vendor scanners and the capture of non-brain tissues, for example, eyes, spinal cord, and skull in the brain MRI. ${ }^{4}$ Pre-processing of the brain MRI data is essential for automatic brain tumour segmentation using deep learning models as it determines how the training model performs. Pre-processing techniques of the brain MRI images such as skull stripping, de-noising, registration, and bias field correction are used for the preparation of brain MRI data. The learning models are then trained on this pre-processed data.

The technique proposed by Nyúl et al. ${ }^{5}$ is one of the most widely used methods for intensity normalisation in brain MRI images. The method involves linear piecewise mapping of the intensities of images to a reference scale. Two other techniques are common in use in literature for intensity normalisation of images; normalisation using zOscore (zero mean, unit variance) ${ }^{6}$ and histogram matching. ${ }^{7}$

F. Ullah et al..$^{8}$ explored the effects of different pre-processing techniques on brain MRI segmentation. After extensive literature review and trying out different methods, the team came up with a robust pre-processing framework for automatic brain tumour segmentation. Different pre-processing techniques, like bias field correction, intensity normalisation, histogram equalisation and Gibbs ringing artefact removal were employed to analyse their effects and find out an optimal pre-processing method for training. Results showed that Gibbs ringing artefact removal followed by bias field correction proved to be the most effective. The pre-processing technique was then applied to the brain MRI images for the

1 C. Jaspin Jeba Sheela, G. Suganthi, "An Efficient Denoising of Impulse Noise from MRI Using Adaptive Switching Modified Decision Based Unsymmetric Trimmed Median Filter," Biomedical Signal Processing and Control 55, (2020): 101657

2 Xiaotian Wang, Guangming Shi, Peiyu Zhang, Jinjian Wu, Fu Li, Yantao Wang and He Jiang, "High Quality Impulse Noise Removal Via NonUniform Sampling and Autoregressive Modelling Based Super-Resolution," IET Image Processing, (2016): 304-313

3 C. Helen Sulochana and S. A. Praylin Selva Blessy, "Intensity Inhomogeneity Correction in Brain MR Images Based on Filtering Method. In Handbook of Research on Applications and Implementations of Machine Learning Techniques," IGI Global, (2020): 96-110

4 José Bernal, Kaisar Kushibar, D. Asfaw, S. Valverde, A. Oliver, R. Martí and X. Lladó, “Deep Convolutional Neural Networks for Brain Image Analysis on Magnetic Resonance Imaging: A Review," Artificial Intelligence in Medicine 95, (2019): 64-81

5 Nyúl LG, Udupa JK and Zhang X, "New Variants of a Method of MRI Scale Standardisation," IEEE Transactions on Medical Imaging 19, 2 (2000): 143-150

6 Pereira S, Pinto A, Alves V and Silva C A, "Brain Tumor Segmentation Using Convolutional Neural Networks in MRI Images," IEEE Transactions on Medical Imaging, 35, 5 (2016): 1240-1251

7 Sun X, Shi L, Luo Y, Yang W, Li H, Liang P and Wang D, "Histogram-Based Normalisation Technique on Human Brain Magnetic Resonance Images from Different Acquisition," Biomedical Engineering Online 14, 1 (2015): 73

8 Faizad Ullah, Shahabuddin Ansari, Anam Abid and Muhammad Salman Khan, "MRI Brain Image Enhancement for Tumor Segmentation using 3D U-Net," Magnetic Resonance in Medicine. (In review) 
training of the deep learning model. This research can be further extended to applications involving MRI modality images of other body organs.

\section{Liver and Liver Tumour Segmentation}

Liver cancer is among the leading causes of deaths around the globe. ${ }^{1}$ Computer-aided disease diagnosis through liver and liver tumour segmentation is essential for timely detection and diagnosis of the disease. 3D medical images are used for automatic liver and liver tumour segmentation and classification. One of the challenging tasks in this approach is the pre-processing of $3 \mathrm{D}$ medical images like computer tomography $(\mathrm{CT})$ images. The challenge arises due to similar intensities of the liver with adjacent body organs, varied contrast level, and irregular shape of the liver, etc. Discussion of optimal pre-processing techniques for liver and liver tumour segmentation cannot be found in the research literature. Globally, researchers are working on developing a computer-aided diagnostic (CAD) system for liver and liver tumour segmentation, classification, and diagnosis of liver diseases. Traditional CAD systems are based on manual segmentation techniques which are timeconsuming and reliant on the operator. This may cause errors and/or the misdiagnosis of the disease. CAD systems make the diagnosis process more efficient and robust.

Islam et $a .^{2}$ investigated the performance of different pre-processing techniques for segmentation of liver from MRI and CT scan images which often proves to be a challenging task due to issues like varying contrast levels, noise, and non-uniform shape of the liver. The research findings show that the combination of three techniques; HU-windowing, z-score normalization and median filtering achieved the most optimal performance results with Dice coefficient of $96.93 \%, 90.77 \%$ and $90.84 \%$ for training, validation, and testing, respectively.

\section{COVID-19 Detection}

COVID-19 (Coronavirus) is a disease that has affected several millions of people around the globe. As of December 2020, a cumulative number of over 79 million cases and over 1.7 million mortalities have been reported since the start of the pandemic. ${ }^{3,4}$ The mortalities from

\footnotetext{
Cancer.org, "Key Statistics About Liver Cancer," American Cancer Society, https://www.cancer.org/cancer/liver-cancer/about/what-is-keystatistics

2 Muhammad Islam, Kaleem Nawaz Khan and Muhammad Salman Khan, "Evaluation of Preprocessing Techniques for U-Net Based Automated Liver Segmentation," Accepted in Proceeding, IEEE International Conference on Artificial Intelligence, (5-7 April 2021)

3 "Weekly Epidemiological Update-COVID-19," World Health Organization, https://www.who.int/publications/m/item/weeklyepidemiological-update---29-december-2020

4 “COVID-19 Coronavirus Pandemic," https://www.worldometers.info/coronavirus/
} 
COVID-19 were the result of the failure of respiratory functions, which failed other body organs. The principal clinical tool that is currently being used extensively for the testing and screening of COVID-19 is the Reverse transcription-polymerase chain reaction (RT-PCR). ${ }^{1}$ This test is less-sensitive, expensive, requires specialised healthcare personnel for interpretation of the results. A technology tool enabling a more accurate and rapid diagnosis of COVID-19 is crucial in the current scenario. An easy and accessible tool is X-Ray and CT imaging for COVID-19 diagnosis using Al. During the pandemic, there was an immense burden on healthcare systems and the doctor's time is limited due to the large number of patients attending outdoor emergencies.

X-ray images and CT scans are widely used by radiology experts to perform image-based COVID-19 diagnosis. ${ }^{2,3}$ These images are hard to diagnose for specialists as they contain hundreds of slices. Automatic detection of the virus through Al-based techniques thus becomes highly desirable. Screening through computer-aided diagnosis (CAD) saves lives through early detection and accurate diagnosis of the disease.

Chowdhry et al. ${ }^{4}$ proposed an image-based automatic COVID-19 diagnosis technique from X-Ray images (chest). A database was created which consisted of the chest X-Rays images (COVID-19 positive cases and normal plus viral pneumonia X-Ray images). The practical aim of the research was to propose a robust technology tool for the detection of COVID-19 from $X$-ray images through the application of deep-learning algorithms applied to pre-trained images. This maximises the detection accuracy as well. The deep neural networks were trained for the classification of two different schemes, that is, normal and COVID-19 positive and viral, normal, and COVID-19 positive with and without image improvement. High classification accuracy of $98.3 \%$ was achieved.

\footnotetext{
1 Udugama, B., Kadhiresan, P., Kozlowski, H. N., Malekjahani, A., Osborne, M., Li, V., Chen, H., Mubareka, S., Gubbay, J. B., and Chan, W, "Diagnosing COVID-19: The Disease and Tools for Detection," ACS Nano 14, 4 (2020): 3822-3835. https://doi.org/10.1021/acsnano.0c02624

2 Feng Shi, Jun Wang, Jun Shi, Ziyan Wu, Qian Wang, Zhenyu Tang, Kelei He, Yinghuan Shi and Dinggang Shen, "Review of Artificial Intelligence Techniques in Imaging Data Acquisition, Segmentation and Diagnosis for COVID-19," IEEE Reviews in Biomedical Engineering, (6 April 2020)

3 Tawsifur Rahman, Amith Khandakar, Yazan Qiblawey, Anas Tahir, Serkan Kiranyaz, Saad Bin Abul Kashem, Mohammad Tariqul Islam, Somaya Al Maadeed, Susu M. Zughaier, Muhammad Salman Khan and Muhammad E.H. Chowdhury, "Exploring the Effect of Image Enhancement Techniques on COVID-19 Detection using Chest X-rays Images.", Computers in Biology and Medicine, (4 March 2021)

4 Muhammad E.H. Chowdhury, Tawsifur Rahman, Amith Khandakar, Rashid Mazhar, Muhammad A. Kadir, Zaid bin Mahbub, Khandakar R. Islam, Muhammad S. Khan, Atif Iqbal, N. Al-Emadi, Mamun B.I. Reaz and Mohammad T. Islam, "Can AI help in Screening Viral and COVID-19 Pneumonia?" IEEE Access 8, (2020):132665 - 132676
} 
Gaal et al. ${ }^{1}$ proposed a lung segmentation technique (Attention-U-Net) in X-Ray images for pneumonia. The method can be extended to automatically diagnose COVID-19 and other related diseases easily.Zhang et al. ${ }^{2}$ also proposed a model for the automatic detection of COVID-19 detection from X-Ray images. The model performs two jobs: the classification between positive COVID-19 and negative COVID-19 images plus anomaly scoring. Results show that the model's accuracy is $95 \%$ with a sensitivity and specificity of $96.0 \%$ and $70.7 \%$, respectively.

Jin et al. $^{3}$ used chest computed tomography (CT) images from 496 COVID-19 positive subjects and 1385 negative COVID-19 subjects for the segmentation of lung and identification of slices of the positive COVID-19 cases using a 2D CNN (convolutional neural network)-based model. Results show that the technique achieved an accuracy of $97 \%$ and a sensitivity and specificity of $94.1 \%$ and $95.5 \%$ respectively.

Global research trends show an increased interest in applying Al and digital health tools in different areas of medicine. While Muslim scientists are involved in global health research as individual researchers and scientists; there is still a need for the Muslim community to come together for a combined effort for a more robust healthcare infrastructure in Muslim populations. The Islamic countries need to be self-sufficient with the governments utilising resources effectively by designing health infrastructure and investing in policy-making that will cater to the unique needs of the local Muslim populations.

\section{Conclusion}

Muslims made breakthrough discoveries and inventions in the golden period of Islamic development. The ripple effects of their contributions to medical science and other fields are carried forward into modern-day science and technology. The notable Muslim scientists were scholars of many disciplines holding expertise in multiple areas of science like medicine, chemistry, physics, mathematics, astronomy including others. For the present and future Muslim generations, this is a source of inspiration to carry forward the legacy of these exceptional names. A lot must be done to bring back the time like the Islamic Golden Age.

\footnotetext{
G. Gaál, B. Maga, and A. Lukács, “Attention U-Net Based Adversarial Architectures for Chest X-ray Lung Segmentation," arXiv preprint arXiv:2003.10304 (2020)

2 J. Zhang, Y. Xie, Y. Li, C. Shen, and Y. Xia, "COVID-19 Screening on Chest X-ray Images using Deep Learning-Based Anomaly Detection," arXiv:2003.12338, 2020

3 S. Jin, B. Wang, H. Xu, C. Luo, L. Wei, W. Zhao, et al., "Al-Assisted CT Imaging Analysis for COVID-19 Screening: Building and Deploying a Medical Al System in Four Weeks," MedRxiv, (2020)
} 
Scientific information and knowledge need to be made available to those who do not have exclusive access to the resources through governmental initiatives and actions. Muslim scientists and researchers from around the world also need to develop a collaborative spirit to extend and share meaningful individual scientific work. This enables the effective transfer of knowledge in Muslim societies around the globe and provides opportunities for innovative technology development. One of the main targets of the collaborative initiatives among the Muslim scientists is to strengthen the knowledge-based economy, enabling science and technology to be utilised in a manner that promotes local manufacturing, nourishes cuttingedge research and development, creates wealth generation opportunities, and improves the socio-economic standing of individuals. This also develops a base for creativity, innovation, and the generation of new ideas. Substantial efforts on a governmental level in Muslim countries for policymaking and investment in transformational governance for implementation of digital health and Al can radically change the health and healthcare outcomes. 